\title{
Não há outro caminho que não a colaboração!
}

\author{
“There is no other way than collaboration!”
}

“No hay otro camino a no ser la colaboración!”

\author{
ANDRÉ LUIS NOGUEIRA DA SILVA ${ }^{12}$ \\ ${ }^{1}$ FundaçÃo InStITUto BRAsileiro de GEOgRAFIA E ESTATística (IBGE), NATAL - RN, BRASIL \\ ${ }^{2}$ Fundação Getulio Vargas (FGV EAESP) / Escola de Administração de EMPreSAS de SÃo Paulo, SÃo PAULO - SP, BRASIL
}

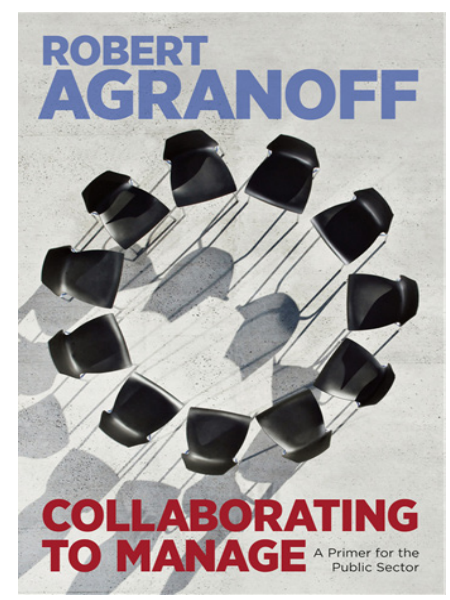

AGRANOFF, R. Collaborating to manage: a primer for the public sector. Washington: Georgetown University Press, 2012. 270 p. ISBN 978-1-58901-916-4.

Palavras-chave: Gestão colaborativa. Administração pública. Agências públicas.

Keywords: Collaborative management. Public administration. Public agencies.

Palabras clave: Gestión colaborativa. Administración pública. Agencias públicas.

Não há outro caminho que não a colaboração! Este é o principal desafio a ser enfrentado pelo setor público na atualidade, segundo Robert Agranoff (2012). Nessa obra, que se propõe teórico-prática, o cientista político envereda pelo campo da gestão pública contemporânea, incorporando não só sua trajetória de pesquisas sobre relações intergovernamentais, mas trazendo, também, uma importante contribuição da teoria de redes e da própria administração de empresas. Seu principal argumento é que a gestão colaborativa se apresenta como a mais nova e emergente maneira de resolver problemas coletivos e, assim, de dar resolutividade às agências públicas diante das rápidas demandas que surgem no mundo globalizado e interativo.

O livro ancora-se na ideia de que há problemas tão intratáveis, tão difíceis de serem resolvidos, que os caminhos para enfrentálos são desconhecidos, complexos ou precisam da atuação de múltiplos atores, inclusive privados, para serem solucionados. O conceito de gestão colaborativa surge, então, como uma definição teórico-prática para a compreensão do processo de gerir empreendimentos públicos - políticas ou programas - que preconizam atuação conjunta. Agranoff (2012) o descreve como sendo o processo de facilitar e operar recursos em arranjos multiorganizacionais para tratar problemas coletivos, cuja resolução não pode ocorrer pela atuação de organizações isoladamente. Trata-se de uma definição mais abrangente do que a perspectiva de governança colaborativa proposta por Ansell e Gash (2007), que, embora também enfatize a participação de distintos atores na gestão de políticas públicas, concebe apenas arranjos decisórios formais. Ao reunir elementos basilares da gestão colaborativa, o autor busca contribuir não apenas com o debate acadêmico, mas também ajudar gestores públicos a lidarem com os problemas que enfrentam em seu cotidiano. Tal objetivo emoldura a estrutura da narrativa e a própria linguagem adotada pelo autor, que opta por iniciar todos os 9 capítulos do livro com a apresentação de um caso concreto. Segundo Agranoff (2012, p. 1, tradução nossa), "o livro não deve ser lido como um manual de instruções, mas como um meio de conectar o pensamento à ação" (The book should not be read as an operating manual but as a way to link thought to action).

O capítulo 1, "Gerir é colaborar" (To manage is to collaborate), apresenta os objetivos e a justificativa do livro, explicitando suas premissas teórico-conceituais e construindo uma síntese das outras partes do texto. Agranoff (2012) indica 3 estudos que constituem a base do conhecimento acerca da colaboração enquanto prática administrativa. O primeiro é Wagenaar (2004), sobre burocracia interativa, que caracteriza as transações administrativas como: a) situadas; b) envoltas por conhecimento; c) ações; e (4) desenvolvidas por meio de interação entre as partes. O segundo é Keith Sawyer (2007), que aborda o poder criativo da colaboração. Em suas pesquisas, Sawyer (2007) chegou à conclusão de que o engajamento em esforços colaborativos propicia maior criatividade, que se origina quando as pessoas trabalham juntas em uma situação com pico de atividades. Por fim, o terceiro estudo traz o conceito de interoperabilidade como relevante dimensão teórica da gestão colaborativa. 
O trabalho de Jenkins (2006) demonstra que a comunicação recíproca entre os setores operacional e de planejamento é elemento-chave para "destravar" o processo de colaboração.

Tratando de aspectos conceituais, Agranoff (2012) realça a existência de um mix de atividades colaborativas, que podem variar de conexões mais soltas e fluidas a arranjos estruturais mais duradouros. Essas conexões podem ocorrer de maneira legal ou informal. $O$ autor também categoriza os tipos de colaboração a partir de 2 variáveis: a) o nível de engajamento das partes (mínimo e máximo); e b) a frequência de interação (intermitente ou regular). Alerta, no entanto, que tal classificação é mais útil para demonstrar que há diferentes tipos de colaboração. Ela revela, ademais, distintas formas de valer-se da sinergia como lógica para atuação conjunta. Os conceitos de organizações condutivas e de redes também são empregados como essenciais para compreender a gestão colaborativa, tanto que são aprofundados nos capítulos 3 e 6 , respectivamente.

O capítulo 2, "Intergovernamentalização e gestão pública colaborativa" (Intergovernmentalization and collaborative public management), demonstra como as relações intergovernamentais aprofundaram a necessidade de colaboração. Agranoff (2012) coloca que a gestão intergovernamental não envolve só os diferentes níveis de governo, mas também abarca distintos atores governamentais e não governamentais. A colaboração, portanto, supõe interações verticais e horizontais, estatais e não estatais:

Gestão colaborativa começa, assim, com uma compreensão básica das estruturas e da interdependência no sistema. Programas e organizações existem em uma gama complexa de oportunidades que, se combinadas e/ou conectadas, podem atuar na solução de alguns dos problemas mais intratáveis da sociedade (AGRANOFF, 2012, p. 50, tradução nossa). (Collaborative management thus begins with a basic understanding of the structures and interdependencies in the system. Programs and delivery organizations exist in a complex array of opportunities that, if combined and/or connected, can work at solving some of society's most intractable problems)

O capítulo seguinte aborda um conceito essencial para a gestão colaborativa: a agência pública condutiva. Saint-Onge e Armstrong (2004) entendem que uma organização é condutiva quando consegue garantir a qualidade de seus serviços e manter o fluxo de conhecimento mesmo em um cenário de constante mudança e adequação às necessidades dos clientes e do mercado. Para isso, faz-se necessário que a organização crie parcerias, construa alianças e performe sua equipe para que atuem através de fronteiras organizacionais e funcionais. Agranoff (2012) acredita que esse conceito pode ser transmutado para o setor público, colocando que é cada vez mais necessário que as organizações públicas sejam mais permeáveis ao ambiente externo. A intergovernamentalização, a proliferação de novas ferramentas de governança e o aumento da interação com o terceiro setor e com o setor privado implicam na necessidade de aumento da condutividade das agências públicas.

No capítulo 4, "Forjando acordos externos" (Forging external agreements), a preocupação do autor recai sobre os dispositivos cooperativos firmados junto às entidades externas ao governo, como as organizações não governamentais (ONGs). Analisando esse instrumental - contratos de gestão, subvenções e acordos multipartes -, Agranoff (2012) aponta que sua constituição envolve uma série de atividades que ocorrem fora da agência pública e através de fronteiras organizacionais. Negociar premiações pelo alcance de metas, interpretar e informar os objetivos e as regras, prestar assistência técnica e construir redes são algumas das atividades que fazem parte da rotina da agência condutiva.

Gerir conexões da agência condutiva presume contrapartidas entre as partes. Esse é o mote de abertura do capítulo seguinte, "Gerindo conexões da agência" (Managing agency connections). Seu foco é aprofundar a questão da interação entre as agências condutivas e as organizações com as quais elas trabalham. Agranoff (2012) resgata os estudos sobre implementação de políticas públicas para abordar a questão operacional dos empreendimentos colaborativos. Traz, então, a noção de interoperabilidade, afirmando referir-se à "programação regular envolvendo duas ou mais entidades para as quais políticas e processos operacionais têm sido articulados e são executados interativamente em um nível considerável" (AGRANOFF, 2012, p. 122, tradução nossa) ([...] regularized programming involving two or more entities for which operating policies and processes have been articulated and are executed interactively to some considerable degree). A ideia geral é que decisões importantes são tomadas até a efetiva prestação de serviços públicos. Muitas vezes, no percurso do planejamento até a implementação dessas políticas, distintas entidades são envolvidas, sejam públicas, privadas ou do terceiro setor. Isso maximiza a importância de fazer com que tais arranjos cooperativos tenham uma gestão interoperável.

Considerando que a constituição de redes de políticas públicas é o mais alto nível colaborativo, o autor dedica um capítulo à abordagem específica da gestão desses arranjos. "Processando colaboração em profundidade: gerindo em redes" (Processing deeping collaboration: managing in networks) versa sobre o processo operacional das redes, demonstrando que, apesar de 
seu caráter auto-organizativo, elas também precisam de liderança. Recai sobre os gestores públicos o papel de promover sua gestão, cujo principal desafio é acomodar os distintos interesses e prover sinergia no alcance do objetivo para o qual foram constituídas. Para Agranoff (2012), as redes compartilham das seguintes características: a) status identificável e/ou permanente; b) encontros regulares; c) sistema de comunicação definível; d) possuem líderes e participantes; e) constituem forças-tarefas ou grupos de trabalho; f) possuem estrutura de governança; $g$ ) possuem parceiros especificados; e $h$ ) possuem alguma forma de divisão de trabalho ou alocação de tarefas.

O capítulo 7, "Identificando e superando as barreiras para a colaboração" (Identifying and overcoming the barriers to Collaboration), discute as possíveis falhas da gestão colaborativa e aponta maneiras para tentar evitá-las. $\mathrm{O}$ autor identifica 7 impeditivos à colaboração: a) proteção do domínio/território de atuação da instituição; b) aversão ao risco; c) perda de tempo e custo de oportunidade; d) natureza multicultural e multiorganizacional dos potenciais participantes; e) esforço de poder; f) retenção de recursos previamente acordados; e g) barreiras específicas de determinadas políticas públicas. A principal maneira de superação de tais entraves seria a construção de confiança, que pode ser sedimentada pela instituição de processos de deliberação participativa e pelo cumprimento de compromissos acordados.

O capítulo 8, "A nova organização pública" (The new public organization), apresenta, assim, uma organização burocrática amplamente condutiva, uma estrutura organizacional aberta e capaz de transitar e articular-se em diferentes fronteiras. Ela consegue mobilizar esforços, atores e entidades para atingir seus objetivos e, principalmente, resolver problemas intratáveis, impossíveis de ser solucionados por uma única organização. $O$ uso de ferramentas digitais, o aprofundamento do engajamento cívico, o foco no uso do conhecimento no processo decisório, o aprendizado conjunto e, acima de tudo, a organização em rede são elementos que demarcam essa nova configuração das agências governamentais. A rigidez e a hierarquia isolacionista dão lugar à fluidez, ao dinamismo e, em especial, a ininterruptos processos colaborativos.

“Colaboração funciona!" (Collaboration works!) é o capítulo que encerra o livro e o próprio título denota seu viés normativo. Antes de argumentar a favor da gestão colaborativa, Agranoff (2012) coloca a colaboração como estratégia para atuar em um mundo cada vez mais interconectado, demarcado pela contínua complexificação das relações sociais e institucionais. Um mundo no qual a necessidade de mudanças não cessa e que, por consequência, exige das organizações, sejam públicas ou privadas, maior agilidade para responder a demandas que surgem de maneira rápida e, muitas vezes, espontânea. São essas questões contemporâneas ou macroestruturais que provocam a passagem de uma era de controle para um mundo de adaptabilidade. Trata-se do esgotamento das teorias clássicas da administração, cujo substrato se encontra nos modelos fordista, taylorista e weberiano, e da passagem para um novo paradigma, baseado em redes, informação e colaboração, cuja marca são organizações de fronteiras abertas (Open Boundary Organization). Essa nova era não implica no esvaziamento do poder da burocracia pública. Pelo contrário, ela demanda um reposicionamento de suas funções, visando agregar valor público a sua atuação.

Dessa forma, o livro oferece um novo olhar sobre o dualismo entre administração e administração pública, debate iniciado em clássico texto de Woodrow Wilson (1887) e sempre presente quando o assunto é a reforma do Estado (ABRUCIO, 1998). Apesar das diferenças, Agranoff (2012) encontra na análise processual e nos condicionantes globalizantes uma ponte conceitual: a colaboração. Desmistificando a existência de uma rígida dualidade, ele demonstra que os dois campos de estudo devem ajudar-se tanto em termos práticos quanto no desenvolvimento de instrumentais teórico-metodológico. Quando traz a noção de colaboração como condição premente, inclusive para o mundo das organizações empresariais, onde a competição é comumente alçada enquanto substrato de origem e sobrevivência, Agranoff (2012) contradiz a literatura da ciência política que concebe o processo de agregação de preferências como um jogo de soma zero. Os estudos e os casos de sucesso que apresenta evidenciam ser possível, sim, mobilizar entidades com distintos interesses para atuar em prol de objetivos comuns. Para o autor, a gestão pública colaborativa não só é possível, como também é o único caminho para resolução dos complexos problemas contemporâneos. 


\section{REFERÊNCIAS}

ABRUCIO, F. L. Os avanços e os dilemas do modelo pós-burocrático: a reforma da administração pública à luz da experiência internacional recente. In: BRESSER-PEREIRA, L. C.; SPINK, P. (Org.). Reforma do Estado e administração pública gerencial. Rio de Janeiro: Ed. FGV, 1998. p. 173-199.

AGRANOFF, R. Collaborating to manage: a primer for the public sector. Washington: Georgetown University Press, 2012.

ANSELL, C.; GASH, A. Collaborative governance in theory and practice. Journal of Public Administration Research and Theory, v. 18, n. 4, p. 543-571, 2007.
JENKINS, W. O. Collaboration over adaptation: the case for interoperable communications in homeland security. Public Administration Review, v. 66, n. 3, p. 319-322, 2006.

SAINT-ONGE, H.; ARMSTRONG, C. The Conductive Organization. Amsterdam: Elsevier, 2004.

SAWYER, K. Group genius: the creative power of collaboration. New York: Basic Books, 2007.

WAGENAAR, H. Knowing the rules: administrative work as practice. Public Administration Review, v. 64, n. 6, p. 643-655, 2004.

WILSON, W. The study of administration. Political Science Quarterly, v. 2, n. 2, p. 197-222, 1887. 